\title{
高強度EUV-FEL光による原子・分子のイオン化過程と高調波シード化FEL
}

\author{
岩崎 純史 ${ }^{1,2,3}$, 佐藤 克洋 ${ }^{3}$, 大和田 成起 ${ }^{1,3}$, 富樫 格 ${ }^{4}$, 高橋 栄治 ${ }^{5}$, 緑川 克美 ${ }^{5}$, \\ 青山 誠, 山川 考一 ${ }^{6}$ ，神成 文彦 ${ }^{7}$, 柳下 明 $^{8}$, 永園 充 $^{3}$, 矢橋 牧名 ${ }^{3}$, 石川 哲也 ${ }^{3}$, 山内 薰 ${ }^{1,2,3}$ \\ ${ }^{1}$ 東京大学大学院 理学系研究科化学専攻 ( \\ 2東京大学大学院 理学系研究科超高速強光子場科学研究センター（Ｔ113-0033 東京都文京区本郷7-3-1) \\ ${ }^{3}$ 理化学研究所 播磨研究所放射光科学総合研究センターXFEL研究開発部門 ( T 679-5148 兵庫県佐用郡佐用町光都1-1-1) \\ ${ }^{4}$ 高輝度光科学研究センター ( ₹ 679-5148 兵庫県佐用郡佐用町光都1-1-1) \\ 5 理化学研究所基幹研究所エクストリームフォトニクス研究グループ (†351-0198 埼玉県和光市広沢2-1) \\ ${ }^{6}$ 日本原子力研究開発機構 関西光科学研究所 ( 个619-0215 京都府木津川市梅美台8-1-7) \\ 7慶應義塾大学 理工学研究科 ( $\overline{7} 223-8522$ 神奈川県横浜市港北区日吉3-14-1) \\ 8 高エネルギー加速器科学研究機構 物質材料科学研究所フォトンファクトリー（テ305-0801 茨城県つくば市大穂1-1)
}

\section{Photoionization of Atoms and Molecules by Intense EUV-FEL Pulses and FEL Seeded by High-Order Harmonic of Ultrashort Laser Pulses}

\author{
Atsushi IWASAKI,${ }^{1,2,3}$ Takahiro SATO, ${ }^{3}$ Shigeki OWADA,,${ }^{1,3}$ Tadashi TOGASHI, ${ }^{4}$ Eiji J. TAKAHASHI, ${ }^{5}$ \\ Katsumi MIDORIKAWA, ${ }^{5}$ Makoto AOYAMA, ${ }^{6}$ Koichi YAMAKAWA, ${ }^{6}$ Fumihiko KANNARI, ${ }^{7}$ \\ Akira YAGISHITA, ${ }^{8}$ Mitsuru NAGASONO, ${ }^{3}$ Makina YABASHI, ${ }^{3}$ \\ Tetsuya ISHIKAWA, ${ }^{3}$ and Kaoru YAMANOUCHI ${ }^{1,2,3}$ \\ ${ }^{1}$ Department of Chemistry, School of Science, the University of Tokyo, 7-3-1 Hongo, Bunkyo-ku, Tokyo 113-0033 \\ ${ }^{2}$ Center of Ultrafast Intense Laser Science, School of Science, the University of Tokyo, 7-3-1 Hongo, Bunkyo-ku, Tokyo 113-0033 \\ ${ }^{3}$ XFEL Research and Development Division, RIKEN SPring-8 Center, RIKEN Harima Institute \\ 1-1-1 Kouto, Sayo-cho, Sayo-gun, Hyogo 679-5148 \\ ${ }^{4}$ Japan Synchrotron Radiation Research Institute, 1-1-1 Kouto, Sayo-cho, Sayo-gun, Hyogo 679-5148 \\ ${ }_{5}^{5}$ Extreme Photonics Research Group, RIKEN Advanced Science Institute, RIKEN, 2-1 Hirosawa, Wako, Saitama $351-0198$ \\ ${ }^{6}$ Kansai Photon Science Institute, Japan Atomic Energy Agency, 8-1-7 Umemidai, Kizukawa-city, Kyoto 619-0215 \\ ${ }^{7}$ Graduate School of Science and Technology, Keio University, 3-14-1 Hiyoshi, Kohoku-ku, Yokohama, Kanagawa $223-8522$ \\ ${ }^{8}$ Photon Factory, Institute of Material Science, 1-1 Oho, Tsukuba, Ibaraki 305-0801
}

(Received June 29, 2012)

The advantages of SPring-8 Compact SASE Source as a light source for spectroscopic measurements in the extreme ultraviolet (EUV) wavelength region are introduced by referring to our recent study of nonlinear photoionization processes of $\mathrm{He}$, in which the absolute two-photon ionization cross sections of $\mathrm{He}$ at four different wavelengths in the $54 \sim 62 \mathrm{~nm}$ region were determined using intense pulses of the freeelectron laser (FEL). In addition, our recent effort to generate intense full-coherent EUV light pulses are introduced, in which significant amplification of the 13th harmonic of ultrashort laser pulses at $800 \mathrm{~nm}$ was achieved by FEL seeded with the 13th harmonic.

Key Words: Extreme ultraviolet (EUV), Free-electron laser (FEL), High-order harmonic, Seeded FEL, Photoionization

1. はじめに

近赤外域の高強度超短パルスレーザー光源の出現は, 近年の光科学研究を格段に発展させた。 その高強度の超 短パルスレーザーの高次高調波として, 波長域が $100 \mathrm{~nm}$ から $10 \mathrm{~nm}$ の極端紫外域 (Extreme ultraviolet: EUV) のコヒーレントパルス光源が開発されるようになり， EUV域における原子. 分子の多光子吸収や多光子イオ
ン化などの非線形光学過程が観測されるようになった. 実際, 高次高調波を利用して, $\mathrm{He}^{1)} \mathrm{PH}_{2}{ }^{2)}$ の2光子イオン 化過程が観測されている。 また，このような非線形光学 過程は, アト $\left(10^{-18}\right)$ 秒領域のパルス時間幅の計測に応用

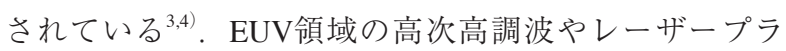
ズマで発生させたEUV光をレーザープラズマによって 増幅するという方式での高輝度EUV光源の開発も進め られているが5-7), 高次の非線形光学過程の観測を実現 
するため, さらに強度の高いEUV域の光源の出現が待 ち望まれていた，EUV域の自由電子レーザー(free electron laser: FEL) は，この期待に応えることのできる 高輝度光源として注目を集めている。

DESY (Deutsches Elektronen-Synchrotron Ein Forschungszentrum der Helmholtz-Gemeinschaft) 研究所に おいては, 2000年Tera-Electronvolt Superconducting Linear Accelerator Test Facilityを用いて, 109 nmの発振が確認さ れ，2007年には13.4 nmの発振をFLASH(Free electron LAser in Hamburg) を用いて達成している (独) 理化学研究所と (財) 高輝度光科学研究センター (JASRI) が共同で組織する, X線自由電子レーザー計画 合同推進本部(XFEL推進本部)によって, SPring-8 Compact SASE Source (SCSS) 試験加速器が, 理化学研究 所播磨研究所に建設された。 2006年には51〜62 nmにお いて発振が確認され ${ }^{9)}$, 日本でも様々な実験研究が行わ れるようになった。

我々の研究グループでは, SCSS試験加速器のEUVFEL光源の立上げ時から, FEL光源を使った実験研究を 推進してきた. $\mathrm{N}_{2}$ が2光子小よび3光子以上のEUV光を 吸収して多価イオンとなり $\mathrm{N}^{+}, \mathrm{N}^{2+}$ フラグメントが生成 することを示し ${ }^{10)}$, さらに, $\mathrm{He}$ の絶対 2 光子イオン化断 面積の波長依存性を明らかにする ${ }^{11,12)}$ などの成果を上げ てきた。

我々は, 将来FEL光源と超短レーザーパルスを用いた ポンプ・プローブ分光の実現が重要になると考え, レー ザー発振器と加速用高周波との同期回路の製作などの技 術開発を進めて来た。その結果, FELパルスとレーザー パルスを用いた時間分解 2 色イオン化収率計測法によっ て，2つのパルスの時間同期計測を可能とした。ささらに 2010年には, これらの実験研究で培ったFELとレーザー との同期技術や計測技術に基づいて, 超短レーザーパル スを用いて発生した高次高調波をアンジュレータに導入 することによって, EUV領域の高次高調波を増幅し, フルコヒーレントなEUVパルスの発生に世界で初めて 成功した.

現在では, X線領域まで発生可能なFEL光源として, 米国スタンフォード大学SLACのLCLS ${ }^{13)}$, 日本の $\mathrm{SACLA}^{14)}$ が既にユーザー運転を開始している。また， DESYのEuropian-FELが2014年に完成を予定している. これらの施設では, 硬X線〜 EUV領域の短波長光パルス を用いた利用実験が可能となり ${ }^{15)}$, 今後の短波長領域に おける非線形光学過程の研究の展開が期待される.

\section{SCSS試験加速器利用の一例：FEL光を用いた Heの2光子イオン化断面積の決定}

我々は, SCSS試験加速器を光源として, Fig. 1に示し た実験装置を用いて, $\mathrm{N}_{2}$ およびHeの多光子イオン化過 程の研究を行った. EUV光パルス $(1 \sim 10 \mu \mathrm{J} / \mathrm{pulse}$, $20 \mathrm{~Hz})$ を， $\mathrm{SiC}$ 製の $f=100 \mathrm{~mm}$ の面ミラーを用いて集 光し, 真空中に噴出した試料ガスビームに集光照射し た. 発生したイオン種を, 飛行時間型質量分析計(Time-

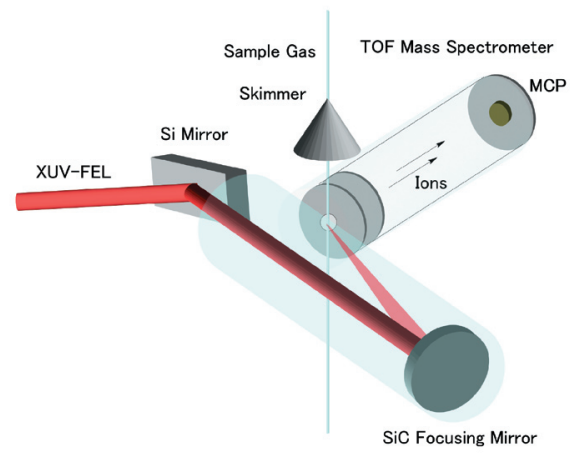

Fig. 1 Experimental setup of the TOF-MS apparatus installed at SCSS Test Accelerator.

of-flight mass spectrometer: TOF-MS)によって質量選別 し，検出したＥＥUV光のパルス出力は，ショット毎に そのスペクトル形状と強度が摇らぐため, TOF質量スペ クトルとFEL強度を1ショット毎に同時に記録した。

SCSS 試験加速器のEUV-FELは, $51 \sim 62 \mathrm{~nm}$ 範囲で発 振波長が可変である. $\mathrm{He}$ の 2 光子イオン断面積は, $58.433 \mathrm{~nm}$ に ${ }^{1} \mathrm{P}(1 s 2 p) \leftarrow 1^{1} \mathrm{~S}\left(1 s^{2}\right)$ 共鳴遷移が存在するた め, 光電場が $10^{13} \sim 10^{14} \mathrm{~W} / \mathrm{cm}^{2}$ にまで強くなると, 光強 度に依存してイオン化断面積が変化することが，これま での理論研究によって予想されていた ${ }^{16-18)}$ 。我々は, FEL光源が波長可変であり，かつ，高強度であるという 特徴を生かして, $\mathrm{He}$ の2光子イオン化収率を計測した。 既にイオン化の絶対断面積が知られている $\mathrm{H}_{2}$ を参照試 料 ${ }^{19)}$ として, $\mathrm{H}_{2}{ }^{+}$と $\mathrm{He}^{+}$を同時に検出し, 収率を比較する ことによって, $\mathrm{He}$ の光子イオン化断面積を求めた.

分子線中の $\mathrm{He}$ と $\mathrm{H}_{2}$ の混合ガス (分圧比 $p(\mathrm{He}): p\left(\mathrm{H}_{2}\right)=$ $97: 3$ )に, EUV-FEL光(波長： $61.4 \mathrm{~nm}, 58.4 \mathrm{~nm}, 56.0 \mathrm{~nm}$,
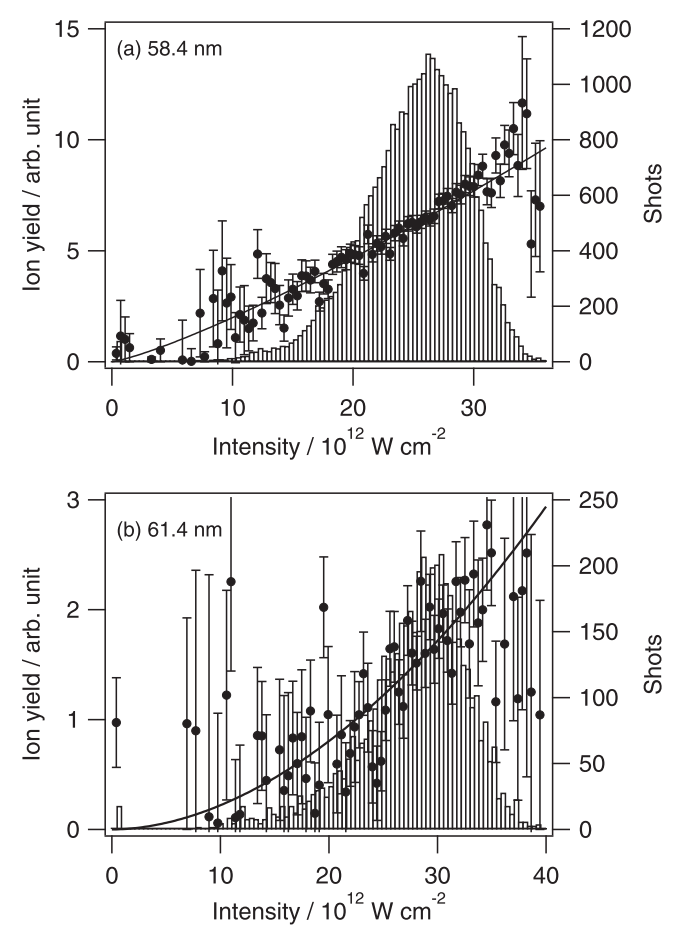

Fig. 2 Ionization yields of $\mathrm{He}$ at (a) $58.4 \mathrm{~nm}$ and (b) $61.4 \mathrm{~nm}$. The height of the histogram in each pulse-energy bin shows the number of shots used to obtain the ionization yield. 
$53.4 \mathrm{~nm})$ を集光した. これらの波長は, 光子のエネル ギーに換算すると $20.2 〜 23.2 \mathrm{eV}$ となり， $\mathrm{H}_{2}$ のイオン化ポ テンシャル $(15.43 \mathrm{eV})$ よりも高いため, $\mathrm{H}_{2}$ は1光子イオ ン化によって $\mathrm{H}_{2}{ }^{+}$となる。 $\mathrm{H}_{2}{ }^{+}$と $\mathrm{He}^{+}$の収量を比較するこ とによってHeの2光子イオン化の絶対断面積を求めるこ とができる。

Fig. 3に, 波長が(a) $58.4 \mathrm{~nm}$ の場合と(b)61.4 nmの場合 について, $\mathrm{He}^{+} の$ 収率のFEL光のパルスエネルギーに対 する依存性を示す。波長が58.4 nmの場合には, イオン 化収率はFELのショット毎のパルスエネルギーに対して 約1次の依存性を示している。これは, $2^{1} \mathrm{P}(1 s 2 p)$ 準位を 経由した共鳴2光子イオン化によって $\mathrm{He}^{+}$が生成するため である。一方， $61.4 \mathrm{~nm}$ においては，2光子イオン化は非 共鳴過程となるため, $\mathrm{He}^{+}$の収率は, パルスエネルギー に対して, 約2次の依存性を示している.

$\mathrm{He}$ のイオン化断面積 $\sigma_{\mathrm{He}}^{(2)}$ は, 今回の実験で得られた $\mathrm{He}$ イオン収率 $Y_{1}, \mathrm{H}_{2}$ 分子イオン収率 $Y_{2}$, 既に報告されてい る各波長における $\mathrm{H}_{2}$ のイオン化断面積 $\sigma_{\mathrm{H}_{2}}{ }^{19)}$ を用いて次 式のように表すことが出来る.

$$
\sigma_{\mathrm{He}}^{(2)}(\lambda, I)=\frac{n_{2} \cdot Y_{1}(\lambda, I) \cdot \sigma_{\mathrm{H}_{2}}(\lambda)}{n_{1} \cdot Y_{2}(\lambda, I)} \cdot\left(\frac{\lambda I}{h c}\right)
$$

ここで, $n_{1}, n_{2}$ は集光点での $\mathrm{He}$ と $\mathrm{H}_{2}$ の濃度を示してい る。なお，本波長領域において，1光子のエネルギーは $\mathrm{He}$ の第一イオン化ポテンシャルより低いため, 1光子で は $\mathrm{He}^{+}$は生成しない.

EUV-FEL光の集光強度が $10^{13} \mathrm{~W} / \mathrm{cm}^{2}$ の場合のHeの2光 子イオン化断面積 $\sigma_{\mathrm{He}}^{(2)}$ として, 波長ごとに, $2.6(6) \times 10^{-52} \mathrm{~cm}^{4} \mathrm{~s}$ $(61.4 \mathrm{~nm}), 23(7) \times 10^{-52} \mathrm{~cm}^{4} \mathrm{~s}(58.4 \mathrm{~nm}), 0.9 \times 10^{-52} \mathrm{~cm}^{4} \mathrm{~s}$ $(56.0 \mathrm{~nm}), 7(5) \times 10^{-52} \mathrm{~cm}^{4} \mathrm{~s}(53.4 \mathrm{~nm})$ の值が得られた。

Fig. 3 に示すように, 得られた2光子イオン化断面積 $\sigma_{\mathrm{He}}^{(2)}$ の值は, R-matrix Floquet法をもちいた理論計算による予

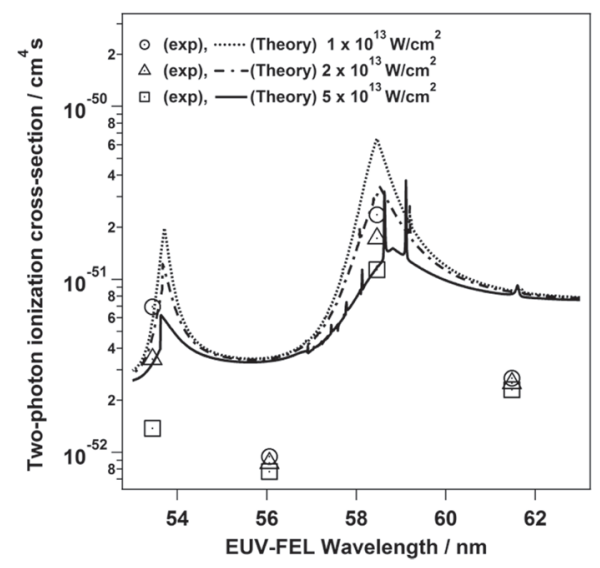

Fig. 3 Variation of the two-photon ionization crosssection of $\mathrm{He}$ as a function of the wavelength. The two-photon cross-sections are shown for the three different light field intensities:(口) $1 \times 10^{12} \mathrm{~W} / \mathrm{cm}^{2}$, ( $\triangle) 2 \times 10^{12} \mathrm{~W} / \mathrm{cm}^{2},(\circ) 5 \times 10^{12} \mathrm{~W} / \mathrm{cm}^{2}$. The theoretical two-photon cross-section curves obtained by R-matrix Floquet method are shown for the corresponding intensities: $1 \times 10^{12} \mathrm{~W} / \mathrm{cm}^{2}$ (dotted line), $2 \times 10^{12} \mathrm{~W} / \mathrm{cm}^{2}$ (dashed line), and $5 \times 10^{12} \mathrm{~W} / \mathrm{cm}^{2}$ (solid line).
測 ${ }^{13)}$ に近い值を示している。

同様に, EUV-FEL光の集光強度が, $1 \times 10^{12} \mathrm{~W} / \mathrm{cm}^{2}$, $2 \times 10^{12} \mathrm{~W} / \mathrm{cm}^{2}, \quad 5 \times 10^{12} \mathrm{~W} / \mathrm{cm}^{2}$ の場合についてもHeの2光 子イオン化断面積 $\sigma_{\mathrm{He}}^{(2)}$ 求めた。 その結果をFig. 3 に示 す。波長 $61.4 \mathrm{~nm}, 56.0 \mathrm{~nm}$ においては，共鳴遷移からは 波長が大きく離れているため, 二光子イオン化断面積 は，集光強度には大きく依存せず，ほぼ一定の值を示し

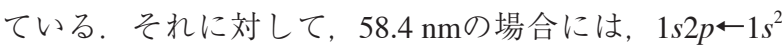
共鳴遷移が存在するため集光強度が増加するに従って二 光子イオン化断面積が減少する。また, $53.4 \mathrm{nmにおけ}$ る2光子イオン化断面積も, FEL強度の増加とともに大 きく減少しており，これは， $1 s 3 p \leftarrow 1 s^{2}$ 共鳴遷移のため であると考えられる。

\section{3. 高次高調波シード型EUV域FELの開発}

\section{1 フルコヒーレントFEL光源開発の必要性}

EUV-FEL光源は，超短パルスレーザーの高次高調波 光源と比較して, そのパルス強度が極めて高いという特 徵を持つ. ところが, このFEL光は, 自然放出光が増幅 された自己増幅自発放射 (Self-amplification of spontaneous emission: SASE)であり，1つの光パルスの中に複数のラ ンダムに増幅されたマイクロパルスが存在し，それぞれ のマイクロパルス間には決まった位相関係は存在しな い.このため，発生したパルスの時間コヒーレンスが低 いと予測されている。つまり，発生するパルス光の強度 は極めて高いものの, そのパルス光の時間プロファイル と波長プロファイルがパルス毎に摇らぐという問題があ るため，EUV-FELパルスの照射に伴って観測される多 価イオン生成過程の解釈を難しいものにしている。

一方で，超短パルスレーザー光による高次高調波光源 は，時間的にも空間的にもコヒーレンスが高いフルコ ヒーレント光であり，パルス毎の時間プロファイルと波 長プロファイルは一定である。この高次高調波光の持つ 優れた性質をFEL光に付与することができれば，高いパ ルス強度と安定した時間と波長のプロファイルを持つ, フルコヒーレント光源を実現することができると期待さ れる。そのためには, 高次高調波をシード光としてアン ジュレータ部に導入すれば良い。しかし，実際には，電 子バンチと高次高調波パルスを，パルス幅( 200 fs) 程 度の時間重なりで重ね, かつ, 空間ビームサイズ(〜 $100 \mu \mathrm{m})$ 程度の空間重なりで重ねなければならない，そ の作業は非常に難度の高いものである。実際，極端紫外 域でFELのシード化を達成したという報告は国内外とも に無い状況であった。

3.2 SCSS試験加速器におけるシードしたEUV-FEL発生 パルスエネルギー30 mJ, 繰り返し $30 \mathrm{~Hz}$ ，パルス幅 $160 \mathrm{fs}$ (FWHM) の超短パルスレーザー光を $f=4,000 \mathrm{~mm}$ の 平凸レンズでXeガスセルに集光し，高次高調波を発生 させた。この時, 超短パルスレーザーの発振器の繰り返 し周波数を， $238 \mathrm{MHz}$ の加速器マスタークロックに同期 するように，共振器内部に設置したピエゾ素子を取り付 
けたミラーをフィードバック制御して動作させた。ま た， 13 次の高調波強度が最も強くなるように，高次高調 波発生条件の最適化を行った。その高調波パルスは2枚 の $\mathrm{SiC}$ の高調波分離ミラーと，2枚の白金製凹面ミラーに よって，1台目のアンジュレータ内に集光した。加速し た電子バンチとレーザーパルスの時間重なりは，スト リークカメラ (浜松ホトニクスFESCA-200)を用いて確 認した。アンジュレータにおいて増幅されたシード光 は，ドライブレーザーの基本波を除去するためのSn フィルターを透過した後, EUV分光器に導入され, ショット毎のスペクトルを記録した。

\section{3 実験結果}

ショット毎に得られた13次高調波スペクトルをFig. 4 (左下)に重ねて示す。レーザー光パルスと電子バンチと のジッターのため，同期が実現された場合においての み，高次高調波が，そのスペクトル特性を維持したまま 増幅されていることが分かる。シードした場合に得られ たFELのパルスエネルギーは1.3 $\mu \mathrm{J}$ であり, Fig. 4(左上)に 示したシード光の強度 $(2 \mathrm{~nJ})$ に比べると 650 倍となる。

また，高次高調波のスペクトルと比較すると，増幅さ れたシード型FELスペクトルの中心波長は $0.3 \mathrm{~nm}$ 程度短 波長側にシフトして観測されていることが分かる。これ はアンジュレータ内におけるシード光の増幅過程におい て, 電子バンチ中の電子が加速されたり減速されたりし た結果, マイクロバンチ構造の圧縮が起こったためと考 えられる。

EUV域における高調波シード型のFEL光源を開発する ためには，電子ビームとレーザーを高い精度で同期する ことが必要である。我々は世界で初めて, EUV域の高 調波シード型FEL光源を実現した ${ }^{20)}$ 。このようなシード 型FEL光を用いれば, その高次高調波を発生させること によって，さらなる短波長化が可能となる。現在，シー ド型FEL光源の更なる短波長化のための技術開発が世界 中で進められている ${ }^{\dagger 1, \uparrow 2)}$. 我々は, このフルコヒーレン トEUV-FELパルスを用いて, 原子や分子の多光子イオ ン化などの非線形光学過程の計測を行う予定である.

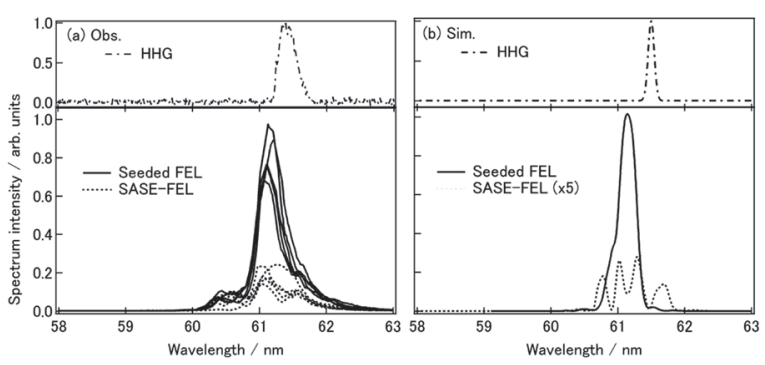

Fig. 4 (a) Observed (left) and (b) simulated (right) spectra of EUV-FEL light. upper: the 13th high-order harmonic (dashed-dotted line); lower: EUV-FEL light seeded with the13th high-order harmonic (solid line) and non-seeded SASE EUV-FEL (dotted line).
X線自由電子レーザー計画合同推進本部の皆様との共 同研究として推進されたものである。ここに御支援，御協 力をいただいた方々に感謝する。また，本研究の一部は， 東京大学を中核機関とする文部科学省科学技術試験研究 委託事業「XFEL光と先端レーザー光による原子・分子 . クラスターのポンプ・プローブ計測」, エクストリーム フォトニクス研究(理化学研究所), ならびにPresident's Discretionary Fund of RIKENの支援を受けて行われた。

\section{参考文献}

1) H. Hasegawa, E. J. Takahashi, Y. Nabekawa, K. L. Ishikawa, and K. Midorikawa: Phys. Rev. A 71 (2005) 023407.

2) K. Hoshina, A. Hishikawa, K. Kato, T. Sako, K. Yamanouchi, E. J. Takahashi, Y. Nabekawa, and K. Midorikawa: J. Phys. B: At. Mol. Opt. Phys. 39 (2006) 813.

3) Y. Nabekawa, T. Shimizu, T. Okino, K. Furusawa, H. Hasegawa, K. Yamanouchi, and K. Midorikawa: Phys. Rev. Lett. 97 (2006) 153904.

4) Y. Nabekawa, T. Shimizu, Y. Furukawa, E. J. Takahashi, and K. Midorikawa: Phys. Rev. Lett. 102 (2009) 213904.

5) $\mathrm{Ph}$. Zeitoun, G. Faivre, S. Sebban, T. Mocek, A. Hallow, M. Fajardo, D. Aubert, Ph. Balcou, F. Burgy, D. Douillet, et al.: Nature 431 (2004) 426.

6) Y. Wang, E. Grnados, M. A. Larotonda, M. Berrill, B. M. Luther, D. Patel, C. S. Menoni, and J. J. Rocca: Phys. Rev. Lett. 97 (2006) 123901.

7) M. Nishikino, M. Tanaka, K. Nagashima, M. Kishimoto, M. Kado, T. Kawachi, K. Sukegawa, Y. Ochi, N. Hasegawa, and K. Kato: Phys. Rev. A 68 (2003) 061802.

8) W. Ackermann, G. Asova, V. Ayvazyan, A. Azima, N. Baboi, J. Bahr, V. Balandin, B. Beutner, A. Brandt, A. Bolzmann, et al.: Nature Photonics 1 (2007) 336

9) T. Shintake, H. Tanaka, T. Hara, T. Tanaka, K. Togawa, M. Yabashi, Y. Otake, Y. Asano, T. Bizen, T. Fukui, et al. : Nature Photon. 2 (2008) 555.

10) T. Sato, T. Okino, K. Yamanouchi, A. Yagishita, F. Kannari, K. Yamakawa, K. Midorikawa, H. Nakano, M. Yabashi, M. Nagasono, et al.: Appl. Phys. Lett. 92 (2008) 154103.

11) T. Sato, A. Iwasaki, K. Ishibashi, T. Okino, K. Yamanouchi, J. Adachi, A. Yagishita, H. Yazawa, F. Kannari, M. Aoyama, et al.: J. Phys. B: At. Mol. Opt. Phys. 16 (2011) 161001.

12) T. Sato, A. Iwasaki, K. Ishibashi, T. Okino, K. Yamanouchi, J. Adachi, A. Yagishita, H. Yazawa, F. Kannari, M. Aoyama, et al.: Europhysics News 42(5) (2011) 10.

13) P. Emma, R. Akre, J. Arthur, R. Bionta, C. Bostedt, J. Bozek, A. Brachmann, P. Bucksbaum, R. Coffee, F.-J. Decker, et al:: Nature Photon. 4 (2010) 641.

14) T. Ishikawa, H. Aoyagi, T. Asaka, Y. Asano, N. Azumi, T. Bizen, H. Ego, K. Fukami, T. Fukui, Y. Furukawa, et al.: Nature Photon. 6 (2012) 540 .

15) A. A. Sorokin, S. V. Bobashev, K. Tiedtke, M. Wellhöfer, and M. Richter: Phys. Rev. A 75 (2007) 051402.

16) H. W. van der Hart and P. Bingham: J. Phys. B: At. Mol. Opt. Phys. 38 (2005) 207.

17) L. A. A. Nikolopoulos and P. Lambropoulos: J. Phys. B: At. Mol. Opt. Phys. 34 (2001) 545.

18) A. Saenz and P. Lambropoulos: J. Phys. B: At. Mol. Opt. Phys. 32 (1999) 5629.

19) Y. M. Chung, E. M. Lee, T. Masuoka, and J. A. R. Samson: J. Chem. Phys. 99 (1993) 885.

20) T. Togashi, E. J. Takahashi, K. Midorikawa, M. Aoyama, K. Yamakawa, T. Sato, A. Iwasaki, S. Owada, T. Okino, K. Yamanouchi, et al.: Opt. Express 19 (2011) 317.

\footnotetext{
${ }^{\dagger 1}$ URL: http://www.elettra.trieste.it/science/top-stories/fisrt-laser-light-in-the-euv-region.html.

${ }^{\dagger 2}$ URL: http://sflash.desy.de/ "An experiment at FLASH for a seeded VUV-FEL”.
} 